\title{
REDUÇÃO DE DANOS: A CONSTRUÇÃO DO ATO NÔMADE E DO CUIDADO COMPARTILHADO
}

\author{
Edna Linhares Garcia* \\ Taís Morgana dos Santos** \\ Rayssa Madalena Feldmann** \\ Marcia de Bastos Braatz** \\ Natália Sulzbach** \\ Carina Ferreira dos Santos** \\ Suzane Beatriz Frantz Krug***
}

RESUMO: Ao longo da história da humanidade podemos perceber o quanto a droga se fez presente no processo civilizatório de diversos povos. Atualmente ela se apresenta como um problema de saúde pública. É neste cenário que a Redução de Danos (RD) emerge como uma política que busca a construção de práticas em saúde voltadas para o cuidado singular. Este estudo busca elucidar as potencialidades desta política, bem como as dificuldades vivenciadas pelos redutores de danos ao longo do seu trabalho no território. É a partir da escuta, alinhada à pesquisa-ação e análise das narrativas, que este estudo se delineia metodologicamente. Possibilitando assim perceber a prática singular e nômade que a $\mathrm{RD}$ protagoniza na construção de cuidado em saúde.

PALAVRAS-CHAVE: Drogas; Redução de danos; Saúde pública.

\section{REDUCING DAMAGE: THE CONSTRUCTION OF THE NOMAD ACT AND SHARED CARE}

ABSTRACT: One may perceive throughout history how drugs were always present within the civilizing process of several peoples. At present, drugs are a public health issue. Reducing Damage emerges as a policy that constructs a health practice for

Doutora em Psicologia Clínica, docente do Departamento de Psicologia, do Programa de Pós-Graduação em Promoção da Saúde (PPGPS) e do Programa de Pós-Graduação em Psicologia (PPGPSI) da Universidade de Santa Cruz do Sul - UNISC, Brasil.

** Psicólogas, graduadas pela Universidade de Santa Cruz do Sul - UNISC, Brasil.

E-mail:marciabraatz@mx2.unisc.br

**: Doutora em Serviço Social, docente do Departamento de Enfermagem e Odontologia, e do Programa de Pós-Graduação em Promoção da Saúde (PPGPS) da Universidade de Santa Cruz do Sul - UNISC, Brasil. 
specific care. Current paper elucidates the potentialities of such policies and the difficulties experienced by damage reducers in the territory. Research is based on listening, research-activity and narrative analysis. $\mathrm{RD}$ comes forward in the construction of health care by perceiving the singular and nomad practices.

KEY WORDS: Drugs; Reducing damages; Public health.

\section{INTRODUÇÃO}

A história das drogas e a trajetória da própria humanidade se confundem, na medida em que o uso de substâncias que alteram os estados da consciência já estava presente nas mais antigas civilizações. Não considerado um fenômeno do contemporâneo, ao longo da linha do tempo, o uso e abuso de drogas lícitas e ilícitas forjou-se no dissemelhante, ocupando diferentes finalidades, que vão desde a recreação até a religiosidade (BUCHER, 1992; MACHADO; BOARINI, 2013; MARANGONI; OLIVEIRA, 2013). Posto isso, uma primeira observação possível, nessa escrita, opera na dimensão dos sentidos assumidos pela droga na cultura, que se deslocam no tempo, na história, nos enunciados, nas leis, na moral, no governo. Trata-se de uma prática antiga, que, na contemporaneidade, investe-se como problemática pública, a saber do Estado e de todos os sujeitos integrantes dele (BRASIL, 2003).

Se na configuração e concepção de saúde que se tem hoje o consumo de drogas é marcado como um problema, tem sido intrínseco nisso a necessidade de resolvê-lo, tratá-lo, moldá-lo, extingui-lo. É proposital a grande quantidade de palavras, que revelam possíveis ações. Isso porque quando se entende que a droga é algo a ser tratado, não são medidos os esforços na tentativa de articular formas de atender aos sujeitos que convivem com ela.

Contudo, todo contato carrega suas marcas de cultura e quando diz respeito àqueles considerados drogados não é diferente. Por muito tempo, droga e sujeito fundem-se, sendo difícil precisar qual era o problema e/ou qual era digno de cuidado. Diz-se de uma intervenção não só médica e psicológica, mas também moral, jurídica, religiosa, estatal (MACHADO; BOARINI, 2013). Assim, precedente à 
estruturação de uma prática que viabilizasse o direito à saúde, à voz e à participação do usuário no seu processo de saúde-doença, o tratamento alicerça-se, em um primeiro momento, na ideia de abstinência e internação (SANTOS; YASUI, 2016). Por muito tempo essa é a única prática pensada, proposta e praticada, estruturando um paradigma criminalizante e punitivo: é excluída a droga da vida do sujeito e o sujeito da vida em sociedade (MORERA; PADILHA; ZEFERINO, 2015).

A Redução de Danos (RD) emerge então como outro curso de cuidado, não necessariamente em oposição ao que vem antes. Pode-se dizer que é paralela. Ao mesmo tempo, a $\mathrm{RD}$ inscreve uma problematização - e um rompimento - dos discursos exclusivos e tratamentos autoritários ofertados aos usuários de drogas. Não se trata mais de anular o indivíduo e sua existência no laço social, mas escutálo de modo atento, singular e integral. A RD não configura, assim, o oposto de abstinência, mas o sinônimo de voz, já que prevê a construção de espaços de fala, escuta e circulação da palavra (DUARTE, 2016; ESTAUBER; GUIMARÃES, 2017).

Dessa maneira, esta escrita coloca-se como recorte de uma pesquisa guardachuva, intitulada Narrativas de adolescentes sobre drogas e os serviços de saúde CAPSia e CAPSad: intersecções possíveis, que propõe a discussão sobre os diferentes setores e instâncias que envolvem o uso e abuso de drogas. O objetivo, aqui, é versar sobre as potencialidades da Política de Redução de Danos, assim como pontuar os principais entraves enfrentados, no cotidiano, por uma equipe de redutores, de uma cidade localizada no interior do Rio Grande do Sul. Para tanto, inicialmente é apresentado um resgate histórico dos lugares ocupados pela $\mathrm{RD}$ até assumir o estatuto de política pública. Em seguida, são apresentados a metodologia e os resultados construídos nas entrevistas com os profissionais da $\mathrm{RD}$.

\subsection{DIREITO À VOZ ÀQUELES SOCIALMENTE EMUDECIDOS}

A RD encontra seus resquícios históricos, no Brasil, ao final da década de 80 do século XX. De acordo com a literatura brasileira, ela foi incorporada como uma estratégia de saúde pública pela primeira vez no país em 1989, no munícipio de Santos, Estado de São Paulo. Ela emerge diante de uma necessidade - ou de um problema público a ser combatido, controlado, tratado, resolvido. Nesse momento, 
o corpo social visualiza nas ruas e nas estatísticas o alto índice de transmissão do vírus HIV, relacionado diretamente ao uso indevido de drogas injetáveis (MESQUITA, 1991). Com o objetivo de diminuir as estatísticas, a RD é constituída inicialmente como uma estratégia de prevenção ao HIV, através do Programa de Trocas de Seringas (PTSs). Ao longo dos anos - e da prática - a RD toma forma, inscrevendo-se enquanto uma estratégia de saúde alternativa àquelas vigentes até então (PASSOS; SOUZA, 2011).

A partir de 2003, a RD é palco de mudanças significativas, marcadas, especialmente, por sua ampliação, ou seja, ela deixa de ser um plano exclusivo dos Programas de DSTS/AIDS e entra como um dispositivo norteador da Política do Ministério da Saúde para Atenção Integral a Usuários de Álcool e Outras Drogas e da Política de Saúde Mental. Com efeito, sua definição ultrapassa a noção inicial de prevenção e esbarra agora na noção de "[...] um novo paradigma ético, clínico e político para a política pública brasileira de saúde de álcool e outras drogas" (PASSOS; SOUZA, 2011, p. 154). Ainda nesse período, foram desenvolvidas diretrizes no Sistema Único de Saúde (SUS) para o tratamento e reabilitação dos usuários de substâncias psicoativas, por meio da implantação de Centros de Atenção Psicossocial de Álcool e outras Drogas (CAPS AD). A Política do Ministério da Saúde, direcionada à atenção integral, busca percorrer a diversidade e as especificidades da população e enseja um discurso de compromisso com os direitos humanos e com a vida. $\mathrm{O}$ objetivo ampara-se no rompimento da dicotomia sujeito-coletividade, tendo em vista os atravessamentos do social no indivíduo e vice-versa (SANTOS; YASUI, 2016).

Atualmente, a $\mathrm{RD}$ é considerada uma estratégia de cuidado que atua diretamente no território e tem a finalidade de minimizar as consequências adversas do uso e/ou abuso de drogas. Em uma narrativa não circunscrita no discurso de guerras às drogas ou criminalização do usuário, suas ações estão pautadas no princípio fundamental de respeito à liberdade de escolha do sujeito. Em outras palavras, preconiza-se a redução dos riscos por meio da escuta a quem é endereçada as intervenções. Os usuários têm a possibilidade do tratamento demarcado pela abstinência, mas também o direito de não o desejar. Como consequência, o usuário tem o poder de refletir sobre suas escolhas e tratamento, reconhecendo e legitimando um sujeito de direitos (SOUZA et al., 2016). 
A $\mathrm{RD}$, ao alcançar o status de política pública, (re)escreve a biografia do cuidado atrelado aos usuários de drogas, abrindo espaço para a efetivação de uma abordagem que não trata baseada em juízos de valor ou princípios moratórios e dogmáticos. A proposta diz respeito a novos caminhos de atenção, que consideram importantes não só o tratamento, mas também a prevenção de doenças e a promoção da saúde (SANTOS; YASUI, 2016). No que diz respeito à prevenção, ressalta-se a oferta de materiais, trocas de substâncias e acompanhamento clínico para amenizar os riscos e danos à saúde do usuário. No contexto da promoção de saúde, sustentase a atenção integral aos sujeitos, bem como a qualificação do acolhimento enquanto ferramenta que possibilita confiança e autocuidado. Somado a isso, aposta-se no diálogo e na valorização dos desejos de cada usuário (CÉZAR; OLIVEIRA, 2017). Em resumo, a anulação tanto da droga quanto do sujeito é substituída pela escuta, pela palavra, pelo acolhimento e pela liberdade.

Ademais, se há a preposição de integralidade, o trabalho da $\mathrm{RD}$ supõe um fazer acompanhado, buscando na intersetorialidade a construção de ações que compreendam o fenômeno do consumo de drogas em sua complexidade dimensional e fatorial. Nesse enlace, o envolvimento de diversos setores permite a modificação de compreensões distorcidas em torno do uso de drogas, a partir de um cuidado realizado na lógica do território e da comunidade onde o sujeito está inserido. A Atenção Básica (AB), porta de entrada no setor saúde, coloca-se como um lugar privilegiado, investindo no fortalecimento de vínculos e no envolvimento dos diferentes atores, a saber profissionais, comunidade, usuários dos serviços, família etc. (SANTOS; YASUI, 2016).

A história da $\mathrm{RD}$, ao ser recontada, mesmo que em poucos parágrafos, imprime a possibilidade de discutir e refletir sobre os cuidados produzidos em torno de uma população que, historicamente, tem seu lugar marcado por discursos e intervenções moratórias e exclusivas. Quando a RD invoca seu caráter de política, também faz ascender outras práticas, que até então eram consideradas impossíveis. $\mathrm{Na}$ direção de dar voz àqueles socialmente emudecidos, tem-se uma política ainda muito recente, que abre espaço para pensar e pesquisar os diferentes processos que a constituem (TRINO et al., 2017). 


\section{A CONSTRUÇÃO DE CAMINHOS METODOLÓGICOS}

Ao desenhar uma pesquisa que tem, em seu cerne, a temática da drogadição em sua complexidade e a necessidade de colocar em pauta as relações singulares que os sujeitos estabelecem com a droga, torna-se imprescindível uma metodologia que, igualmente, legitime uma posição de escuta aos diferentes atores e setores envolvidos. Entre construir, analisar e discutir dados, supõe-se, nisso, uma aproximação ativa não apenas dos enlaces existentes no uso de drogas, mas também do modo como têm sido operadas as políticas públicas de cuidado aos usuários, principalmente no setor da saúde.

Com efeito, optou-se pela pesquisa-ação, marcada pela intersecção entre o conhecer e o fazer, junto a uma realidade e aos participantes que fazem parte dela. Como o próprio nome sugere, a ênfase da metodologia repousa na ideia de ação, construída e decidida de maneira conjunta, abrindo espaço para o protagonismo do pesquisado - com sua própria forma de expressão e linguagem. O conhecimento, nessa direção, é construído para e pela comunidade, uma vez que o saber do sujeito pesquisador e do pesquisado entrecruzam-se a todo o momento, em uma relação de horizontalidade (THIOLLENT; OLIVEIRA, 2016).

A escuta, aqui, delineia-se para além dos discursos dogmáticos, moratórios e patologizantes que irrompem constantemente as intervenções de prevenção e assistência ao uso de drogas. Nisso, a pesquisa, em termos teóricos, sustenta-se na psicanálise, que permite circular o desejo do pesquisador como condição da investigação, em um movimento de afetar e ser afetado. Por meio da associação livre, conceito eminentemente psicanalítico, constrói-se um pesquisar que convida os participantes a acessarem e comunicarem tudo que lhes chega à cabeça, sem qualquer crítica ou seleção. Como consequência, movem-se espaços de fala, plenos de possibilidades, significados e sentidos, reconhecendo o outro como sujeito da linguagem (FREUD, 1996; DALLAZEN et al., 2012).

Logo, elegeram-se, para a análise e discussão dos dados, duas entrevistas realizadas com uma equipe de redutores de danos de um município do interior do Rio Grande do Sul. As entrevistas foram audiogravadas e, posteriormente, transcritas, de modo sequencial, conforme propõe Mary Jane Spink, a fim de visualizar e sublinhar 
os significados, as posições, referências e os sentidos que permeiam os discursos dos sujeitos/atores participantes (SPINK, 2010). Este estudo foi aprovado pelo Comitê de Ética em Pesquisa da Universidade de Santa Cruz do Sul, registrado sob CAAE: 60589116.0.0000.5343.

\section{RESULTADOS E DISCUSSÃO}

"Do sujeito toxicômano muito se fala, mas pouco se escuta" (CONTE, 2004, p. 24).

Com as palavras de Conte (2004), abre-se espaço para pontuar o constante lugar no laço social que é colocado o indivíduo usuário de drogas: o de não direito à palavra. Igualmente, as palavras da autora sugerem o traço comumente polêmico que circunda a prática da $\mathrm{RD}$. Isso porque tal prática, de certa maneira, implica um ato de resistência aos cerceamentos físicos e subjetivos do sujeito toxicômano. Em outras palavras, a política de $\mathrm{RD}$, concretizada na figura dos profissionais, admite a possibilidade de autonomia da pessoa diante de suas escolhas. Existe, nessa perspectiva, a flexibilidade no contrato de cuidado, porque o lugar de linguagem do usuário é legitimado. Mais que isso, o registro da intervenção é impresso na formação do vínculo, por meio da escuta sensível dos desejos, temores, demandas, dificuldades e potencialidades, facilitando o acesso às informações, em uma atitude de (co)responsabilidade (CONTE et al., 2004).

Cada usuário é estimulado a participar do seu processo de tratamento e refletir a partir do que é produzido nele. Em conjunto com os redutores de danos, os indivíduos, para além de meros receptores do saber (científico) do outro, atuam também como gestores das práticas de cuidado. Para Passos e Souza (2011, p. 159), "nas associações de redutores de danos, os usuários de drogas participam como agentes políticos colaboradores na produção de redes de cuidado e de comunicação, criando uma mobilização coletiva, uma gestão do comum”.

$\mathrm{Na}$ esteira dessas prerrogativas, em articulação aos discursos produzidos nas entrevistas com os profissionais, despontam-se três marcadores importantes: o 
primeiro relacionado ao alcance da $\mathrm{RD}$ no território, considerando as transformações do público atendido, nomeado "Os interstícios entre o perfil do usuário e o alcance da RD no território"; o segundo ligado à atuação dos redutores, a partir do conceito de clínica ampliada, nomeado "A RD e a atualização de uma clínica ampliada e política" e, por último, os entraves que (constantemente) permeiam o trabalho da $\mathrm{RD}$, nomeado "Os entraves existentes entre uma lógica que fixa e outra que descola".

\subsection{OS INTERSTÍCIOS ENTRE O PERFIL DO USUÁRIO E O ALCANCE DA RD NO TERRITÓRIO}

O uso de (drogas por) uma mesma pessoa, por exemplo, usando qualquer tipo de droga, independente qual seja, tem se mantido. O que tem aumentado e aparecido mais são casos de usuários [...] a quantidade de pessoas que estão usando, mas não o aumento da droga em si. Estão se conscientizando muito também graças ao nosso trabalho, de se manter em um certo patamar de uso (Narrativa do Redutor 1).

As palavras de um dos redutores anunciam, primeiramente, a dificuldade de traçar um perfil quantitativo, tanto do número de usuários em um determinado território e do índice de uso das diferentes substâncias, quanto dos atendimentos realizados semanais ou mensalmente. Ao mesmo tempo, seu discurso inscreve um aumento no total de usuários que acessam aos serviços de saúde, especialmente à equipe na qual está integrado. Ao assumir uma concepção não mais de problemática individual, mas de ordem pública para a $\mathrm{RD}$, o uso de drogas passa a ser cenário da produção de inúmeras estratégias de cuidado que esbarram na noção de contato, proximidade e escuta do usuário, bem como o contexto que o interpela. Considerase, nisso, a relação que ele estabelece com a droga e o lugar que ela ocupa na sua realidade física e subjetiva (DANTAS; CABRAL; MORAES, 2014). O conceito de autocuidado passa a ser incorporado, possibilitando a construção de processos de autonomia e independência. Daí a importância de uma rede de cuidados que opera no território, em uma dimensão que ultrapassa as estruturas físicas de atendimento.

Para o redutor citado acima, a viabilização de um retrato do uso de drogas e dos usuários torna-se possível somente na intersecção a um maior alcance do 
trabalho realizado pela equipe. Quando é questionado se percebe a existência de novos usuários, delineiam-se, em concomitância, os movimentos que a própria redução tem feito na direção de aperfeiçoar o acolhimento e escuta dos sujeitos que encontram nela a possibilidade não só de tratamento, mas também de fala. Diz, assim, que "não só novos usuários, como também antigos [são atendidos], que nunca vieram no sistema [público de saúde] procurar ajuda. Que já usavam há muitos anos e nunca aparecerem [...] pessoa já com 30 ou 40 anos".

As transformações do perfil da drogadição encontram representação, com isso, no objetivo de reduzir os danos referentes ao uso e abuso de drogas, por meio da ampliação de práticas de cuidado coletivas, acolhimento e contextualização das demandas. A mobilização coletiva e, igualmente, singular organizam espaços de militância dos indivíduos, cujo alicerce está na identificação, diminuição do estigma de doente, incapaz e/ou potencialmente perigoso. Todas essas marchas são frutos de um maior alcance e proximidade entre o sujeito da saúde, o indivíduo com sua linguagem e verdade e o território. Somado a isso, os usuários diminuem o uso ou, até mesmo, abandonam o consumo de drogas, tendo em vista seu envolvimento com a RD na produção de saúde (PASSOS; SOUZA, 2011; GUIMARÃES; MIRANDA; ROCHA, 2017).

A redutora 2 delineia uma narrativa que acompanha a escrita acima, já que considera importantes os deslocamentos que ela e seus colegas realizam nos bairros, estendendo sua prática a pelo menos 33 Estratégias de Saúde da Família (ESFs) da cidade. Para ela, o extramuros dos serviços de saúde implicam outro olhar, não mais apenas para o que chega, mas para aquele a quem se vai ao encontro: "a gente, que convive no território, atende em maior número quem usa crack. Entre álcool e crack, dentro do território e não do serviço, é o crack". A entrevistada ainda complementa a potência que assume o maior alcance aos diversos espaços sociais, físicos e subjetivos presentes na trajetória do usuário. Nas salas de atendimento dos serviços da rede de saúde visualizam-se com frequência o uso do álcool e do crack pelo mesmo usuário. Quando percorrem as ruas da cidade dão sentidos ao entrelaçamento dessas substâncias: "normalmente eles usam cerveja, por causa da lata [para fazer uso do crack] ou cachaça, porque é mais barato".

Diante disso, o primeiro marcador, composto pelo alcance do trabalho 
realizado pelos profissionais redutores de danos no território, está intrinsecamente atrelado à percepção dos entrevistados de um aumento no índice de atendimentos, assim como a possibilidade de esboçar um perfil das demandas. Contudo, umas das discussões possíveis acerca dessa interpretação diz respeito ao questionamento se esse crescente responde apenas à multiplicação do número de usuários ou a uma melhoria do acesso das pessoas à RD. Embora não seja possível afirmar com certeza a resposta para a problemática apontada, são notáveis os avanços que tais práticas têm configurado nos últimos anos, confirmadas na palavra de um dos redutores quando aborda maior conscientização daqueles que são atendidos no território.

\subsection{A RD E A ATUALIZAÇÃO DE UMA CLÍNICA AMPLIADA E POLÍTICA}

Diante da extensão e complexidade envolvidas no trabalho dos profissionais que compõe a RD, mostra-se impossível tornarem fixas suas atuações a um espaço que é medido em metros quadrados. Em outras palavras, elas circulam constantemente no extra e intramuros dos diversos serviços de saúde que caracterizam a rede. Igualmente, não se pode entendê-las através do arcabouço científico tradicional, marcado pela neutralidade e distanciamento dos sujeitos inscritos como detentores do saber.

Merhy (2004) se propôs a refletir sobre os modelos de atenção à saúde, ou seja, aos modos como se produz saúde nos serviços. $O$ autor ressalta que a produção do cuidado se centra na micropolítica do trabalho vivo em ato. Nessa lógica, o autor definiu três tipos de tecnologias que operam na produção do cuidado em saúde: o uso de tecnologias duras (máquinas e instrumentos), tecnologias leveduras, que são definidas pelo conhecimento técnico e as tecnologias leves que são as tecnologias construídas nas relações com o próprio usuário. Para Merhy (1997), no atual modelo de produção de saúde prevalece a utilização das tecnologias duras. Nesta direção, Merhy, Franco e Magalhães Júnior (2003) destacam que o processo de trabalho centrado nas tecnologias leve e leve-duras deve ser uma das premissas para que o serviço seja produtor de cuidado, ou seja, de saúde.

Ao passo que a $\mathrm{RD}$ se configura enquanto uma estratégia de cuidado no território, onde as relações acontecem, disposta a oferecer escuta e acolhimento 
a quem dela necessitar; ela rompe com os discursos exclusivos/discriminatórios e tratamentos autoritários direcionados à população usuária de drogas. É neste sentido que se pode dizer que a RD atua enquanto uma tecnologia leve, pautada na construção do vínculo e em uma escuta que considere as singularidades de cada sujeito; é neste encontro, nesta relação existencial com o usuário que o cuidado acontece e assume papel de protagonista na direção do tratamento de cada sujeito (ESTAUBER; GUIMARÃES, 2017).

Entre os encontros nas salas de atendimento e o caminhar nas ruas da cidade, vê-se construir uma escuta/clínica ampliada, reconhecida também enquanto uma atitude política. Ampliada na medida em que legitima a escuta dos sujeitos em espaços que por muito tempo não eram considerados como lugares de possível linguagem, como, por exemplo, o banco da praça ou o meio-fio da calçada. Política, ao mesmo tempo, porque reivindica um olhar para um ser humano (usuário ou não) que a todo momento é interpelado pelos enunciados do tecido social e do tempo histórico no qual se encontra (TRINO et al., 2017; RODRIGUES; LIMA; HOLANDA, 2018).

Em concordância com tais ideias, a $\mathrm{RD}$, enquanto uma estratégia em saúde pública,

[...] questiona consensos colocados de antemão em torno do usuário e das drogas e reconhece diferentes relações de uso de drogas, uma vez que há a disposição de escutar quem está envolvido com o uso de drogas, possibilitando o reconhecimento da função que esse uso ocupa em sua vida (CONTE et al., 2004, p. 64).

O conceito de clínica ampliada refere-se a uma prática que vai muito além do indivíduo, representando possibilidade de mudanças pessoais, subjetivas e coletivas (DETTMANN; ARAGÃO; MARGOTTOO, 2016). Para tanto, no registro da drogadição e do viés trazido pelos entrevistados da $\mathrm{RD}$, emerge como fundamental o cuidado no território e sua articulação com diferentes serviços e setores. 
Geralmente ficamos no ESF, [...] nas segundas-feiras a gente fica na ESF [...]. Na terça no CAPSad, que daí tem atendimento. Na quarta no CAPSia, na quinta a gente fica na ESF. E na sexta vem pra cá [CAPSad] porque daí as abordagens saem daqui (Narrativa da Redutora 2).

Temos um vínculo muito bom com a rede, com o CRAS (Centro de Referência de Assistência Social), com o CREAS (Centro de Referência Especializado de Assistência Social), na questão da documentação. Temos um assistente social que faz a abordagem com nós [...] que fica encarregado dessa parte da documentação [dos usuários e moradores de rua] (Narrativa do Redutor 1).

Contudo, as ligações entre a $\mathrm{RD}$ e outros setores e disciplinas imprime uma construção diária e constante, não sendo um conceito a priori. Para o redutor 1 , isso é sentido no cotidiano, por meio de pequenas comunicações que expressam um não compartilhar dos mesmos significados de atuação: "nem todos têm essa mentalidade. Isso quando acaba vindo uma mensagem, um bilhetinho escrito "não mandar para a unidade de volta', por exemplo". A redutora 2, nesse momento, enfatiza dizendo: "muitas vezes a gente já recebeu". Para ela, esses movimentos sinalizam para um enunciado implícito de alguns serviços (ou profissionais) de não se compreender como parte de uma rede de saúde, que pressupõe interlocuções entre os diferentes atores.

\subsection{OS ENTRAVES EXISTENTES ENTRE UMA LÓGICA QUE FIXA E OUTRA QUE DESCOLA}

A proposta de uma prática que sugere maior alcance - por sua atuação no território -, bem como a concepção de uma escuta que ultrapassa os aspectos individuais do usuário e os serviços físicos de atendimento, denota uma posição eminentemente nômade. Isso porque os profissionais circulam, andam, movemse, assumindo não apenas um, mas muitos territórios físicos e subjetivos (BRASIL, 2003).

Todavia, essa concepção de cuidado não é homogênea ou universal, ou seja, ela ainda diz respeito muito a $\mathrm{RD}$, mas nem tanto à rede de saúde como um todo. 
Em outras palavras, enquanto os redutores trabalham em uma lógica que descola o cuidado das salas de atendimento, construindo outros espaços como potência de fala, as cidades e os serviços se organizam, de certo modo, ainda em uma lógica que fixa, seja o sujeito usuário ou o profissional que lhe atende. Como consequência, emergem-se entraves que, inicialmente, poderiam ser interpretados apenas como falta de investimentos ou infraestrutura no setor saúde.

Nosso maior impasse é a falta de carro [próprio] na redução mesmo. Porque a gente depende dos outros para poder sair. Às vezes a gente acaba atrapalhando o fluxo de alguns serviços para podermos executar nosso trabalho. Faltam [...] mais recursos, sabe?! (Narrativa da Redutora 2).

Mais [uma questão de] infraestrutura e logística mesmo. A gente precisa de um espaço próprio nosso e de um veículo próprio [...]. A gente faria nosso trabalho melhor. É complicado! Tem que estar se deslocando pro CAPS, o carro precisa estar disponível para ir. Caso contrário, tem que ser solicitado (Narrativa da Redutora 2).

Logo, um dos principais desafios, atualmente, para a equipe de RD é legitimar seu fazer nômade: para maior alcance e proximidade no território, é necessário circular e, para isso, é preciso ferramentas, como um carro próprio, por exemplo. Assim, a disponibilização de recursos se entrelaça a uma perspectiva de cuidado que por muito tempo tem se direcionado às paredes fixas dos serviços, como os CAPSs. Tal afirmativa se sustenta ainda nos discursos dos redutores ao contarem sobre a dependência em relação ao uso dos veículos, que são propriedades de um local e não de uma equipe. Ademais, é perceptível que a falta de recursos se estende ao humano, uma vez que são apenas quatro redutores para as demandas de todo o município. Em termos quantitativos, a atuação da equipe alcança em torno de 33 ESFs e Unidades Básicas de Saúde (UBSs).

Apesar dos avanços conquistados, ainda se reconhece o preconceito e as dificuldades em relação à inserção institucional da equipe da RD no Sistema Único de Saúde e nas políticas sobre drogas (SOUZA et al., 2016). Em Marginalidade ou cidadania: a rede discursiva que configura o trabalbo dos redutores de danos, Nardi e Rigoni (2005) discutem sobre os desafios enfrentados por estes profissionais. 
$\mathrm{ARD}$, ao buscar romper com os modelos anteriores, desconstrói verdades e possibilita a emergência de novas formas de ação em relação ao uso/abuso de drogas. Nesta mesma direção [...] deve ser compreendida como um dispositivo que se diferencia dos modos de intervir que exercitam técnicas de biopoder, posto que não estabelece relações com os usuários pela via da moral, do ressentimento ou do resgate de um estado de saúde ideal estabelecido pela norma médica. A partir dessas noções, pode-se então pensar a inserção da RD e o trabalho dos redutores como um movimento de resistência a um discurso/modo de subjetivar dominante e como uma forma de construção de cidadania (NARDI; RIGONI, 2005, p. 275).

Dessa maneira, as falas dos entrevistados traduzem obstáculos que fogem à atuação da equipe e se inserem no modo como se articula a rede do setor da saúde, com suas próprias concepções de cuidado. Com efeito, não se trata de anular uma visão institucional-física de assistência, mas de permitir que a atuação da $\mathrm{RD}$, entendida aqui como nômade, circule a partir das suas próprias noções do fazer saúde. Não se trata de suprimir um ou outro saber, mas de reconhecer o diferente como uma possibilidade em um determinado tempo e espaço.

\section{CONCLUSÃO}

$\mathrm{O}$ ato de escrever acerca da $\mathrm{RD}$ traduz-se não apenas na apresentação de uma política pública de certo modo ainda muito recente, mas também em uma atitude política, circunscrita na ideia de um cuidado não mais pela via da moral, da religião, do judiciário. Em outras palavras, o tratamento se dá pela via da circulação da palavra, da escuta, do sujeito e do seu conhecimento sobre si mesmo. Trata-se, então, para além de uma nova estratégia de saúde, a afirmação de um determinado fazer/acolher, que até pouco tempo era inexistente ou impensável.

Diante dessas palavras, a $\mathrm{RD}$, enquanto um fazer novo, tem sido palco de inúmeros olhares, pesquisas e ensaios teóricos, que procuram dar conta de uma atuação sem fronteiras, nômade, que vê no território dos sujeitos a potência do cuidado. Nessa escrita, o leitor pôde entrar em contato com um recorte ou, 
melhor dizendo, com algumas das vozes presentes na dinâmica da $\mathrm{RD}$. A entrevista com dois profissionais que integram uma equipe de redutores, emerge como um encontro potente, capaz de fomentar respostas para algumas questões e novos questionamentos em torno de outras.

Dito isso, as narrativas abordadas no texto sinalizam, primeiramente, para uma atuação singular, promotora de protagonismos e implicada com o indivíduo no seu espaço físico, social e subjetivo. Como consequência, parece impossível traçar o perfil das demandas ou do uso de drogas sem considerar a realização de um trabalho que a cada instante tem maior alcance: as intervenções estendem-se aos bairros, às ruas, às praças, às calçadas, aos sujeitos nos seus territórios. Em termos teóricos, diz-se de uma prática pautada na ideia da clínica ampliada, que, nesse contexto, considera possível a criação de outros espaços de fala - para além dos consultórios.

Por fim, os entraves atuais, apontados pelos redutores, dão contornos à necessidade de novas discussões no campo da saúde pública como um todo. Ao sustentar uma atitude nômade, os profissionais encontram desafios que, frequentemente, ultrapassam sua organização enquanto equipe, repousando em uma rede de saúde estruturada ainda muito em torno dos lugares físicos de atendimento. Ao futuro, então, é reservado o desejo de que a $\mathrm{RD}$ continue promovendo modos singulares de escuta e permaneça se desenhando como uma das possibilidades de cuidado no setor saúde.

\section{REFERÊNCIAS}

BRASIL. Ministério da Saúde. Secretaria Executiva. Coordenação Nacional de DST/ Aids. A política do Ministério da Saúde para atenção integral a usuários de álcool e outras drogas. Brasília, 2003.

BUCHER, Richard. Drogas e drogadição no Brasil. Porto Alegre: Artes Médicas, 1992.

CÉZAR, M. A.; OLIVEIRA, M. B. Redução de danos: uma experiência na atenção básica. Mental, v. 11, n. 21, p. 486-500, jul./dez. 2017. Disponível em: http://pepsic. bvsalud.org/scielo.php?script=sci_arttext\&pid=\$1679-44272017000200012. 
Acesso em: 10 out. 2018.

CONTE, M. Psicanálise e redução de danos: articulações possíveis? Revista da Associação Psicanalítica de Porto Alegre, v. 25, p. 23-33, 2004.

CONTE, M. et al. Redução de danos e saúde mental na perspectiva da atenção básica. Boletim da Saúde, v. 18, n. 1, p. 59-76, jan./jun. 2004. Disponível em: http://www.crprs.org.br/upload/files_publications/arquivo27.pdf. Acesso em: 10 out. 2018.

DALLAZEN, L. et al. Sobre a ética em pesquisa na psicanálise. PSICO, Porto Alegre, v. 43, n. 1, p. 47-54, jan./mar. 2012. Disponível em: http://revistaseletronicas.pucrs. br/ojs/index.php/revistapsico/article/view/11098/7618. Acesso em: 9 ago. 2018.

DANTAS, S.; CABRAL, B.; MORAES, M. Sentidos produzidos a partir de experiências de bad trip: drogas, prevenção e redução de danos. Saúde em Debate, Rio de Janeiro, v. 38, n. 102, p. 539-550, jul./set. 2014. Disponível em: http://www.scielo. br/scielo.php?script $=$ sci_arttext\&pid $=$ S0103-11042014000300539. Acesso em: 9 ago. 2018.

DETTMANN, A. P. S.; ARAGÃO, E. M. A.; MARGOTTO, L. R. Uma perspectiva da clínica ampliada: as práticas da psicologia na assistência social. Fractal: Revista de Psicologia, Rio de Janeiro, v. 28, n. 3, p. 362-369, set./dez. 2016. Disponível em: http://www.scielo.br/scielo.php?script $=$ sci_arttext\&pid=S198402922016000300362\&lng=pt\&tlng=pt. Acesso em: 10 nov. 2018.

DUARTE, Marco José de Oliveira. Saúde mental, drogas e território: a garantia de direitos versus a repressão como estratégia de cuidado. In: SOUZA, A. C. (org). Entre pedras e fissuras: a construção da atenção psicossocial de usuários de drogas no Brasil. São Paulo: Hucitec, 2016.

ESTAUBER, A.; GUIMARÃES, C. F. A produção de subjetividade dependente nos CAPSad: problematizando as práticas de cuidado dos usuários de álcool e outras drogas. Saúde em Redes, v. 3, n. 3, p. 273-283, 2017. Disponível em: http://revista. redeunida.org.br/ojs/index.php/rede-unida/article/view/827. Acesso em: 15 nov. 2018. 
FREUD, S. Recomendações aos médicos que exercem a psicanálise. In: Freud S. Obras completas de Sigmund Freud (1912). Rio de Janeiro: Imago, 1996. v. 12, p. 147-59.

GUIMARÃES, L. P.; MIRANDA, M. B. S.; ROCHA, R. V. S. Intensificação de cuidados: afetos e afetações na construção do cuidado em saúde mental, álcool e outras drogas. 2017. 26 f. Monografia (Especialização em Saúde Mental e Atenção Básica) - Escola Bahiana de Medicina e Saúde Pública, Salvador, 2017.

MACHADO, L. V.; BOARINI, M. L. Políticas sobre drogas no Brasil: a estratégia de redução de danos. Psicologia: Ciência e Profissão, v. 33, n. 3, p. 580-595, 2013. Disponível em: http://www.scielo.br/scielo.php?script = sci_abstract\&pid = S141498932013000300006\&lng=e\&tlng=e. Acesso em: 10 jul. 2018.

MARANGONI, R. S.; OLIVEIRA, M. L. F. Fatores desencadeantes do uso de drogas de abuso em mulheres. Texto \& Contexto - Enfermagem, v. 22, n. 3, p. 66270, jul./set. 2013. Disponível em: http://www.scielo.br/scielo.php?script =sci arttext\&pid=S0104-07072013000300012. Acesso em: 9 jun. 2018.

MERHY, E. E.; FRANCO, T. B.; MAGALHÃES JÚNIOR, H. M. Integralidade e transversalidade das necessidades de saúde nas linhas de cuidado.

Movimentos moleculares na micropolítica do trabalho em saúde. 2003. Disponível em: https://www.researchgate.net/publication/268200414. Acesso em: 9 ago. 2018.

MERHY, Emerson Elias. O SUS e um dos seus dilemas: mudar a gestão e a lógica do processo de trabalho em saúde (um ensaio sobre a micropolítica do trabalho vivo). In: FLEURY, Sonia (org.). Saúde e democracia: a luta do CEBES. São Paulo: Lemos Editorial, 1997. p. 125-141.

MERHY, Emerson Elias. O ato de cuidar: a alma dos serviços de saúde. In: BRASIL. Secretaria de Gestão do Trabalho e da Educação na Saúde. Departamento de gestão da Educação na Saúde. VER-SUS Brasil: cadernos de textos. Brasília: Ministério da Saúde, 2004. p. 108-137.

MESQUITA, F. Aids e drogas injetáveis. In: LANCETTI, Antonio (org.). Saúde loucura. 3. ed. São Paulo: Hucitec, 1991. p. 46-53. 
MORERA, J. A. C.; PADILHA, M. I. C. S.; ZEFERINO, M. T. Políticas e estratégias de redução de danos para usuários de drogas. Revista Baiana de Enfermagem, v. 29, n. 1, p. 76-85, jan./mar. 2015. Disponível em: https://portalseer.ufba.br/index.php/ enfermagem/article/view/9046. Acesso em: 9 maio 2018.

NARDI, H. C.; RIGONI, R. Q. Marginalidade ou cidadania? a rede discursiva que configura o trabalho dos redutores de danos. Psicologia em Estudo, v. 10, n. 2, p. 273-282, maio/ago. 2005. Disponível em: https://ume.ufrgs.br/bitstream/ handle/10183/98529/000492771.pdf?sequence=1\&isAllowed=y. Acesso em: 9 jun . 2018.

PASSOS, E. H.; SOUZA, T. P. Redução de danos e saúde pública: construções alternativas à política global de "guerra às drogas". Psicologia \& Sociedade, v. 23, n. 1, p. 154-162, 2011. Disponível em: http://www.scielo.br/scielo.php?pid=S0102$71822011000100017 \&$ script $=$ sci_abstract\&tlng = pt. Acesso em: 10 jul. 2018.

RODRIGUES, J. S.; LIMA, A. F.; HOLANDA, R. B. Identidade, drogas e saúde mental: narrativas de pessoas em situação de rua. Psicologia: Ciência e Profissão, v. 38, n. 3, p. 424-436, jul./set. 2018. Disponível em: http://www.scielo.br/scielo. php?script $=$ sci_arttext\&pid=S1414-98932018000300424\&lng=pt\&tlng=pt. Acesso em: 15 out. 2018.

SANTOS, C. E.; YASUI, S. Muito além do Caps AD: o cuidado no território e na vida. In: SOUZA, A. C. (org.). Entre pedras e fissuras: a construção da atenção psicossocial de usuários de drogas no Brasil. São Paulo: Hucitec, 2016.

SPINK, M. J. Linguagem e produção de sentidos no cotidiano. Rio de Janeiro: Centro Edelstein de Pesquisas Sociais, 2010.

SOUZA, P. M. S. S. de et al. Clínica nômade voz da rua: políticas de drogas e redução de danos. Humanas \& Sociais Aplicadas, v. 6, n. 16, p. 53-58, 2016. Disponível em: http://www.seer.perspectivasonline.com.br/index.php/humanas sociais_e_aplicadas/article/view/1041. Acesso em: 15 out. 2018.

THIOLLENT, M.; OLIVEIRA, L. Participação, cooperação, colaboração na relação dos dispositivos de investigação com a esfera da ação sob a perspectiva da pesquisa-ação. CIAIQ2016, v. 3, p. 357-366, 2016. 
TRINO, A. T. et al. Promoção do cuidado com estratégias de redução de danos na cena de uso do bairro de Neves em São Gonçalo (RJ). Cadernos do Cuidado, v. 1, n. 1, p. 18-32, 2017. Disponível em: https://editora.observatoriodocuidado.org/ index.php/CC/article/view/54. Acesso em: 15 out. 2018.

Recebido em: 10/12/2018

Aceito em: 31/05/2019 